\title{
Lo banal como instrumento de nación: La importancia de la selección colombiana en la activación de procesos identitarios
}

\section{Banal as an instrument of nation: The importance of the Colombian national team in triggering identity processes}

\author{
Nicolás Roa Vargas ${ }^{1}$ \\ Andrés Mauricio Salcedo Rodríguez ${ }^{2}$ \\ Universidad Nacional de Colombia
}

\begin{abstract}
Resumen
El retorno del mundial de fútbol a Latinoamérica y de la Selección Colombia desbordó el sentimiento de patriotismo que siempre surge en los eventos deportivos. Las grandes victorias o perdidas nacionales (aparte de las regionales) han sido noticias momentáneas, con una duración proporcional a la carga emocional impresa por la gente, pero que posteriormente se aliviana y se desvanece, perdiendo interés mediático. Durante el Mundial se vio cómo la selección colombiana fue capaz de revitalizar un sentimiento nacional realmente identificable debido a que sirvió como elemento de comunión de la gente, sin importar divisiones regionales y de clase. Este artículo muestra, precisamente, cómo la participación del seleccionado nacional fue un instrumento con una gran inversión simbólica aprovechada y manejada por los medios, élites políticas y grupos económicos con la creación de un imaginario publicitario, pero que, a la vez, es finalmente el pueblo el que reproduce estas representaciones nacionales o bien las resignifica para establecer una relación más fuerte de pertenencia e identidad nacional.
\end{abstract}

Palabras clave: nacionalismo banal, Selección Colombia, mediatización cultural, Mundial Brasil 2014.

\begin{abstract}
The return of the FIFA World Cup to Latin America and of the Colombian National Team to this event overflowed the feeling of patriotism that grows in sports events. The big national victories (or failures) had been momentary news with a duration related with the emotional charge of the people, but at the end decreases and loses the media interest. During the 2014 World Cup was clear how the Colombian National Team was capable of revitalize a clearly recognizable national feeling, because served as element of communion, no matter regional and class divisions. This article show, in fact, how the participation of the national team was an instrument with a large investment symbolic, exploited and manipulated by the media, political elites and economic groups, with the creation of an advertising imaginary, but, also, at the end, people are the responsible of reproduce these national representations, or they redefine it, to establish a stronger relationship of belonging and national identity.
\end{abstract}

Keywords: banal Nationalism, Colombian national team, mediation of culture, World Cup Brazil 2014

Recibido: 17 de noviembre de 2014 Aceptado: 19 de diciembre de 2014

1 Sociólogo y estudiante en la Maestría en Educación (Línea Educación y Ciencias Sociales) de la Universidad Nacional. Contacto: roavargasbecerra@msn.com

2 Sociólogo de la Universidad Nacional. Contacto: andresalcedo5@hotmail.com 


\section{Fabricando una comunidad imaginada con el fútbol}

El Mundial en Brasil fundó una ilusión de lo bello que sería para un país como Colombia coronarse como campeón del mundo. Aunque en realidad este sentimiento fuese común para la mayoría de países participantes, para los cuales el Mundial pudiese servir como medio para invocar esa llamada justicia divina e imponerse a los grandes monstruos, para poderlos ver con el cuello totalmente erguido y que por eso hace falta la misma mano de Dios para poderlos abofetear. Incluso el mismo anfitrión, que se sabía superior (se autoproclamaba o melhor do mundo), supo qué era sentirse diminuto ante una imponente Alemania. Tal derrota lo hizo volver a su realidad de protestas sociales, su gran aliado, la FIFA, lo estaba depredando.

En últimas, nuestra ilusión se esfumó, al ser sorprendidos siendo presas de la historia y de la realidad, viendo cómo la catalogada como la mejor selección Colombia de los últimos tiempos no pudo derrotar a un deslucido Brasil. Sin embargo, la imaginación hizo lo suyo. Esa ficción del mundial sirvió para que entraran al juego diferentes expresiones de la nacionalidad como una construcción, que de una consciencia colectiva (en el caso colombiano con diferencias tan marcadas entre grupos regionales y capas sociales) trascendiese a una consciencia nacional. La apelación a una comunidad imaginada, redefinida por el fútbol, muestra cómo se va gestando una creación colectiva en torno a la nación.

No obstante, se caería en un error al pretender otorgarle una naturaleza espontánea a este tipo de configuración. Aquel sentimiento de comunidad y unión está permeado por las diferentes connotaciones de nacionalismo que desde los medios de comunicación se han transmitido. Ya que en el Mundial de Brasil, como en ningún otro evento, el uso de las tecnologías de la información fueron mediadoras directas para la construcción de una comunidad de sentido, e independiente de que sus razones sean comerciales, de entretenimiento o ambas, aquellas reprodujeron y exaltaron una forma específica de imaginar la nación.

En este sentido, habría que ver cuál es el carácter que adquieren estos artefactos culturales en lo que es ahora una "sociedad red" (Castells: 1999) y cómo estos son capaces de producir imaginarios de nación. La sensación de simultaneidad hacia un grupo nacional se habrá intensificado en un contexto como el actual con el uso de las tecnologías de la comunicación, ya que (verbigracia: el evento acá abordado) el uso de estos medios permitirán la transmisión en vivo de estos espectáculos considerados de "interés nacional", así como posibilitarán conocer casi que de forma instantánea sus repercusiones en la prensa y las redes sociales, o incluso interactuar con otras personas de diferentes puntos geográficos compartiendo el agrado o el disgusto despertado por un partido de fútbol. Todos estos son aspectos que mostrarán, tal como Benedict Anderson lo argumentaba con la convergencia entre el capitalismo y la imprenta (1993: 75), la importancia que tendrán este tipo de artefactos de la cultura para crear sentimientos de afiliación, o bien, fortalecer un imaginario de nación. Así, habría que indagar el papel que adquieren estos dispositivos en un ámbito globalizado donde la creación de una industria del espectáculo se convierte en una herramienta eficaz para movilizar representaciones imaginadas de la nación, que además de tener un carácter cultural, adquirirán un sentido de utilidad buscando mostrar y vender una imagen estereotipada de "lo nacional".

\section{La mediatización de los productos culturales y la "movilización de la nación" en torno a un mundial de fútbol}

"Mostremos lo buenos que podemos llegar a ser los colombianos". "Esta es Colombia: tierra de gente pujante y trabajadora, que cuando se esfuerza puede llegar a impresionar al mundo". Estas fueron algunas de las frases emitidas desde los medios de comunicación, cuando se hablaba y se hacía el cubrimiento del papel del 
seleccionado nacional en el Mundial de fútbol; fenómeno que invita a reflexionar el significado que se le quiso dar desde la mayoría de medios, y lo que realmente fue y dejó al país.

En efecto, el Mundial fue para los medios el escenario perfecto para poder manifestar y exacerbar el sentimiento nacionalista: en primera medida, las manifestaciones culturales que más identifica a los connacionales como colombianos son el fútbol y la música (Encuesta nacional de cultura, 2002). Esto por cuanto la construcción de referentes identitarios compartidos por la mayoría de colombianos se construye desde la mediatización de determinados productos culturales, que están más emparentados a las lógicas comerciales y el consumo en masa. Así, pues, la música y el deporte son las actividades culturales más activas al momento de conectarse a las lógicas mediáticas y comerciales, capaces de introducir creativamente nuevas realidades, nuevos públicos y nuevos modos de consumo sin necesariamente abandonar sus propias condiciones culturales.

"Los medios se convierten en dispositivos culturales que dan lugar a rutinas, prácticas de consumo, relaciones con la tecnología, formatos o narrativas particulares. Si la televisión se desenvuelve a través de la instantaneidad, la fragmentación y las mezclas audiovisuales, la radio restituye la conversación y la interacción más cálida con sus audiencias, mientras que la prensa combina conocimientos, información y entretenimiento" (Rey, 2002:26). Así pues, no es gratuito el rótulo que reciben los medios de comunicación como industrias culturales, ya que son capaces de movilizar y cristalizar formas de identificación colectiva hacia determinadas expresiones culturales, que al momento de manifestar un tipo de sentimiento nacionalista ocupan una posición privilegiada. Tal como lo muestra Gómez, los lugares de memoria tradicionales han perdido para la mayoría de colombianos su significado y su poder de convocatoria, siendo sustituidos por un repertorio de prácticas colectivas con un matiz comercial, que él denomina "actos recreativos"
(2004:101). De esta forma también se construye un cambio de las formas de identificación con la nación: ante la continua apatía sobre símbolos tradicionales que representan un tipo de nacionalismo folclórico, surge un nacionalismo popular que destaca las experiencias cotidianas de la gente como un lugar de memoria común.

De allí se explicaría cómo el Mundial de fútbol cobró tanta relevancia. Podría afirmarse que la connotación que adquiere la participación de la Selección Colombia en un evento como este obtiene una importancia mayoritariamente simbólica, que sobrepasa en valor a lo que en términos reales el evento abarca. Entonces, el Mundial evocará por un lado una representación "moderna" de identidad nacional, que además se condensa en el fútbol, una expresión popular de la cotidianidad de un país que, como Dávila afirma: "se ve en el fútbol $y$, además, este constituye un reflejo de la sociedad misma, capaz de construir y acoger identidades nutridas por un sentimiento nacionalista" (2001:87). Por otro lado, está lo que Martín-Barbero señalará acerca de la necesidad de algunos grupos de representar una imagen distorsionada del país. En tanto que se confundirá el relato nacional como identificación colectiva de la nación, con aquella necesidad infundada desde la política y los medios de comunicación, de querer adquirir una "buena imagen" para ser reconocidos en el mundo y así crear una identidad impostada del ser colombiano (2001:23).

\section{“En colombia el fútbol se baila": el nacionalismo banal y sus alcances}

Puesto que rara vez se ha visto que un evento de otras características (político, cultural, social) reúna con tanta facilidad a la ya fragmentada nación colombiana carente históricamente de una expresión cultural homogenizante, es interesante observar la manera en la que el Mundial fue capaz de capturar la atención de la gente hacia un sentimiento patrio que en muchos casos es tan difuso, y está atomizado en una gran variedad de referentes colectivos de identificación. 
Para poner un ejemplo: un elemento típico de mercadeo adquiere sentido y hasta es adoptado por la gente como algo propio, como una fiel representación de lo que podría identificarse con aquel sentir de "lo colombiano". El tan publicitado lema de la marca cervecera patrocinadora de la selección colombiana, tan propio de las pautas que hacen miles de compañías en el mundo, exaltando unas supuestas características distintivas de cada grupo nacional ante un evento como el campeonato Mundial de Fútbol, encajó de manera ideal con las exultantes celebraciones de los jugadores de "La Selección". Cada partido fue una oportunidad para olvidar de manera transitoria la realidad y, por fin, celebrar con un baile: ritual catárquico hecho con licor que menguaba una sed de triunfos palpables y hacían que espontáneamente el espíritu de la juerga se fuera apoderando de los que quisieran sentirse protagonistas de las victorias gestadas en la tierra de la zamba. Ahora, toda fiesta se acaba y con ella queda su desorden, su resaca y hasta sus prohibiciones, empero de las lagunas mentales suscitadas consciente $o$ inconscientemente queda algún recuerdo de lo bailado.

Un sonsonete popularizado por ídolos flamantes: "ras, tas tas...", que así como se referiría la modesta prensa de este país, con cada gol harían su danza de la victoria... ... y aún sigue sonando.

¿Hasta qué punto hay un distanciamiento entre las prácticas culturales de distintos grupos sociales? ¿Cuándo pueden converger? El Mundial de fútbol alcanzó una connotación mayor a la de un simple evento deportivo; podría decirse que se constituyó en un instrumento con suficiente poder para movilizar diferentes capas sociales en torno a la novedad y el resurgimiento de un sentimiento nacionalista, significado en una manifestación tan popular como el fútbol y la fiesta. Esto, además, dio una imagen al mundo de lo que es lo nacional, que por lo general termina asimilándose a una construcción basada en un "tropicalismo" muy propio de las regiones costeras del país.
El fútbol y la nación fue una eficaz combinación que llegó a ser lo suficientemente fuerte para despertar un ya cansado sentimiento de identidad nacional que se niega a responder a los gastados símbolos nacionalistas de siempre. En este sentido, cabe resaltar el papel que cumple el fútbol como una manifestación cultural de carácter masivo, capaz de generar (según la connotación que adquiera el espectáculo) un sentimiento comunitario o, si se quiere, la posibilidad de imaginarse una nación. Así, no es de extrañar la rimbombancia que adquirió este evento deportivo en las propagandas de los medios de comunicación, pero también en la política con los discursos, tweets y acciones del presidente Santos, que en tiempos electorales buscaba afanosamente mostrar su apoyo a la Selección y por medio de metáforas relacionarlo con el apoyo a los diálogos con las FARC como una sola causa política de su gobierno. Así, la coyuntura deportiva se prestó como el medio más eficaz para poder hablar de un "nosotros" uniforme: "nuestro país", "nuestra selección", "nuestra paz" etc. Empero, en lo local también se ve reflejado el uso del fútbol como una herramienta de aprovechamiento de las élites políticas y económicas: en algunos municipios el regalo de camisetas de la Selección Colombia a las comunidades con el nombre estampado del político en cuestión era un acto más que frecuente.

Frente a este aspecto puede verse cómo en el consumo cultural lo masivo no excluye la presencia de los grupos hegemónicos, más bien la cultura popular es vista como un elemento comunitario que puede generar correspondencia entre grupos, pero también como un instrumento de provecho de la clase dominante para obtener legitimidad política, o bien consolidar la industria del espectáculo.

En este sentido, no hay que desestimar la importanciadetodoestetipoderepresentaciones populares y sus productos culturales, que pueden dar lugar a la conformación de referentes de nacionalismo, y aunque sean catalogados como <banales>, manifiestan ser de gran valor para establecer una identificación colectiva en la gente en su percepción de nación: 
[...] lo popular no está ausente, negado $e$ impedido de también relatar, tejer o narrar percepciones de nación; un modo y contenido cultural que le es propio $y$, muchas veces más dinámico que la debilitada burguesía colombiana que no ha logrado socializar al país en los valores que coincidan con su dominación, por su escasa decisión cultural (Bolívar, Ferro y Dávila, 2001: 10).

Con todo, resulta interesante observar cómo, más allá de la heterogeneidad entre grupos sociales, lo banal logra ser visto en algunos casos como un medio para establecer elementos de comunión; que también puede llegar a entenderse como una respuesta ante los múltiples intentos fallidos que desde la élite, a lo largo de la construcción de nación, se han hecho para llegar a establecer una homogeneidad cultural en el país.

Ha sido el interés de este artículo mostrar que el entendimiento de la identidad nacional a partir de este tipo de manifestaciones que pueden ser consideradas banales, no obstante, servirá como una herramienta para comprender cómo se representa la nueva posición que ocupa la cultura en un ámbito globalizado. Recordando a Marx: el capitalismo se haría mundo cuando se torne en cultura; y más cuando tanto el mundo como este nuevo opio son redondos.

\section{Referencias}

Anderson, B. (1997). Comunidades imaginadas, México: Fondo de Cultura Económica.

Bolívar, Ferro \& Dávila, (2001). Nación y sociedad contemporánea, Bogotá: Ministerio de Cultura.

Bolívar, Ferro \& Dávila, (2001). Belleza, Fútbol y Religiosidad Popular, Bogotá: Ministerio de Cultura.

Castells, M. (1999). La era de la Información: economía, sociedad y cultura, México: Siglo XXI Editores.

Martín-Barbero, J. (2001) Imaginarios de nación. Pensar en medio de la tormenta. Bogotá: Ministerio de Cultura. Cuadernos de nación.

Rey, G. et al (2002). Culturas simultáneas, lecturas de la encuesta nacional de cultura". Cuadernos de nación. Bogotá: Ministerio de Cultura. 
